\title{
ESTABILIDADE DE PRODUTOS DE PEQUI (Caryocar coriaceum Wittm) SOB CONGELAMENTO EM DIFERENTES TIPOS DE EMBALAGENS ${ }^{1}$
}

\author{
JOACI PEREIRA DE SOUZA², RICARDO ELESBÃO ALVES ${ }^{3}$, EDY DE SOUSA BRITO4, \\ DIJAUMA HONÓRIO NOGUEIRA ${ }^{5}$, JANICE RIBEIRO LIMA ${ }^{6}$
}

RESUMO - Avaliaram-se as características de qualidade de pequi (C. coriaceum) congelado e acondicionado em diferentes embalagens, armazenados a $-18^{\circ} \mathrm{C}$, durante 300 dias. Os frutos, coletados na safra de 2009/2010, foram descascados, obtendo-se assim os caroços, que, após sanificados, foram submetidos a 3 tipos de embalagens: 1 - Cortados em lâminas de aproximadamente $2 \mathrm{~mm}$ de espessura de polpa e seladas a vácuo em polietileno de alta densidade (PEAD); 2 - Caroços embalados e selados a vácuo em sacos de PEAD; 3 - Caroços dispostos em bandejas de poliestireno expandido e envoltos por filme plástico. As amostras foram avaliadas aos $0 ; 60 ; 120 ; 180 ; 240$ e 300 dias de armazenamento. Utilizou-se um delineamento inteiramente casualizado, em esquema fatorial, e os resultados foram submetidos a análises de variância e regressão. O congelamento do pequi submetido aos três tipos de acondicionamento foi eficiente na preservação das características de qualidade como: pH, acidez titulável e açúcares totais durante 300 dias de armazenamento. Os teores de carotenoides e polifenóis extraíveis totais mostraram redução acentuada no acondicionamento da polpa a vácuo. A forma mais indicada de congelamento do pequi para a manutenção da cromaticidade é o acondicionamento do caroço a vácuo ou em bandeja com filme de PVC.

Termos para indexação: Armazenamento, acondicionamento, características de qualidade.

\section{PEQUI (CaryocarcoriaceumWittm) PRODUCT STABILITY UNDER FREEZING IN DIFFERENT TYPES OF PACKAGING}

\begin{abstract}
It was evaluated the quality characteristic of pequi fruit (C. coriaceum) under freezing and put up in different packages, stored at $-18^{\circ} \mathrm{C}$ for 300 days. The fruits collected in 2009/2010 crop were peeled thus obtaining the kernel, which after sanitized were submitted to three types of packages: 1 - cut into slices of approximately $2 \mathrm{~mm}$ pulp thickness and vacuum sealed with high density polyethylene (HDPE) bags; 2 - kernel packaged in vacuum sealed bags HDPE; 3 - arranged in polystyrene trays and wrapped in plastic film. The samples were evaluated at 0,60,120, 180, 240 and 300 days of storage. It was used a completely randomized design in factorial and the results were submitted to analysis of variance and regression. The freezing of pequi fruit subjected to three types of packaging was efficient in preserving the quality characteristics such as $\mathrm{pH}$, tritatable acidity and total sugars during 300 days of storage. The levels of total extractable polyphenols and carotenoids showed marked reduction in pulp packaging vacuum. The most suitable freezing of pequi fruit to maintain the chromaticity is the kernel of vacuum packaging or tray with PVC film.
\end{abstract}

Index terms: Storage, packaging, quality characteristics.

\footnotetext{
${ }^{1}$ (Trabalho 126-13). Parte da tese de doutorado do primeiro autor, apresentado à UFERSA para a obtenção do Título de Doutor. Auxílio à pesquisa da FUNCAP.

${ }^{2}$ D.Sc. em Fitotecnia, Prof. IFCE-Câmpus Iguatu-Depto. de Desenvolvimento de Ensino. E-mail: soupe@zipmail.com.br

${ }^{3}$ D.Sc. em Ciências dos Alimentos, Pesquisador da EMBRAPA - Agroindústria Tropical. E-mail: ricardo.alves@embrapa.br

${ }^{4}$ D.Sc. em Ciências dos Alimentos, Pesquisador da EMBRAPA-Agroindústria Tropical. E-mail: edy@cnpat.embrapa.br

${ }^{5}$ D.Sc. em Fitotecnia, Prof. IFCE-Câmpus Iguatu Depto. de Desenvolvimento de Ensino. E-mail: dijaumah@yahoo.br

${ }^{6}$ D.Sc. em Ciências dos Alimentos, Pesquisador da EMBRAPA-Agroindústria Tropical. Email: janice@cnpat.embrapa.br
} 


\section{INTRODUÇÃO}

O pequizeiro (Caryocar coriaceum Wittm) constitui um recurso genético de grande relevância para a região do Cariri cearense e outras áreas do Piauí e Pernambuco, onde seus frutos são comercializados e apreciados na alimentação de forma in natura ou na confecção de pratos regionais.

Entretanto, a espécie é sazonal, e o pico de produção ocorre nos meses de janeiro a março. $\mathrm{O}$ extrativismo e a comercialização do pequi representam fonte significativa de renda para as famílias de catadores da região da Chapada do Araripe. O problema da sazonalidade está assentado na disponibilidade de frutos no período da entressafra. Contudo, apesar de o fruto ser rico em nutrientes e apresentar diversos usos, o pequi, especialmente o $C$. coriaceum, não tem merecido a devida atenção da pesquisa. Poucos são os estudos encontrados na literatura envolvendo a biometria (SILVA; MEDEIROS FILHO, 2006; OLIVEIRA et al., 2009) e a caracterização química nutricional dos frutos dessa espécie (OLIVEIRA et al., 2010).

O congelamento apresenta-se como alternativa viável à manutenção das características organolépticas e nutricionais, tornando-o mais próximo do produto fresco, principalmente quando comparado com o produto processado que, muitas vezes, é submetido a tratamentos químicos (DELGADO; SUN, 2001). O congelamento rápido é o mais indicado, visto que ocasiona a formação de pequenos cristais de gelo, principalmente no meio intracelular, evitando desidratação celular e rompimento das membranas devido à formação de grandes cristais de gelo (COLLA; HERNANDEZ, 2003).

O congelamento tem a finalidade de preservar alimentos armazenados por longos períodos. Entretanto, alterações podem ocorrer mesmo a temperaturas abaixo de $0^{\circ} \mathrm{C}$. A velocidade de congelamento e a estabilidade da temperatura durante o armazenamento são fatores que auxiliam na estabilidade do alimento (YAMASHITA et al., 2003). O pequi (Caryocar brasiliense Camb) é um fruto indicado para ser comercializado a longo prazo por meio do congelamento, pois preserva boa parte de seu valor nutricional e atributos importantes para o consumidor de alimentos congelados, como cor, firmeza e microestrutura (GONÇALVES et al., 2010). Contudo, não foram encontradas informações bibliográficas do congelamento de pequi (C. coriaceum).

Considerando a escassez de pesquisas sobre os efeitos do congelamento em frutos de pequizeiro, o presente trabalho teve como objetivo avaliar as características de qualidade do caroço e lâminas de pequi (C. coriaceum) sob congelamento $\left(-18^{\circ} \mathrm{C}\right)$, em diferentes tipos de embalagens, e armazenados por 300 dias.

\section{MATERIAL E MÉTODOS}

A coleta de frutos de pequi foi realizada durante as safras de 2009/2010, no mês de fevereiro, na Chapada do Araripe-CE, em áreas produtoras de fruto do município de Jardim, no Cariri Cearense. Os frutos foram adquiridos dos catadores de pequi que coletaram diretamente do chão, na manhã do dia seguinte de sua queda. Os frutos foram acondicionados em caixas plásticas e transportados para o Laboratório de Processamento de Frutos e Hortaliças do Setor de Agroindústria do Instituto Federal de Educação, Ciência e Tecnologia do Ceará - Câmpus Iguatu, onde foram lavados em água corrente para a retirada de sujidades e, em seguida, selecionados para eliminar frutos apodrecidos ou amassados com exposição do caroço. Depois de lavados e selecionados, os frutos foram imersos numa solução de hipoclorito de sódio $\left(200 \mathrm{mg} / \mathrm{L}^{-1}\right)$ durante 15 minutos, com o objetivo de reduzir a carga microbiana do campo. O preparo inicial das amostras envolveu o descascamento, que constou de um corte na região equatorial para a retirada da casca e a obtenção do caroço (pirênio). Nesta etapa, foi realizada nova seleção, visando a eliminar os caroços que apresentavam manchas escuras ou danos provocados por pragas. Inicialmente, os caroços foram imersos numa solução de hipoclorito de sódio $(50 \mathrm{mg} / \mathrm{L})$ por 15 minutos, para sanificação, e em seguida lavados em água corrente e colocados em repouso para drenar o excesso de líquido acumulado. Depois de secos, os caroços foram submetidos aos seguintes tratamentos: 1 - Cortados em lâminas (lascas) de polpa de aproximadamente $2 \mathrm{~mm}$ de espessura e imediatamente imersas em solução de ácido cítrico a 10\%, durante 10 minutos, para evitar escurecimento. Em seguida, as lâminas foram lavadas em água corrente e acondicionadas em sacos de polietileno de alta densidade (PEAD) de 16 micras, com selagem a vácuo; 2 - Embalados e selados a vácuo em sacos de PEAD de 16 micras; 3 -Dispostos em bandejas de poliestireno expandido e envoltos por filme de cloreto de polivinil (PVC).

As amostras foram armazenadas em freezer doméstico a $-18^{\circ} \mathrm{C}$, e as avaliações das características de qualidade foram realizadas aos $0 ; 60 ; 120 ; 180$; 240 e 300 dias de armazenamento no Laboratório de Tecnologia e Fisiologia Pós-Colheita da EMBRAPA - Agroindústria tropical. Para a realização das análises, a polpa foi retirada manualmente com o auxílio de uma faca de inox e depois triturada em 
multiprocessador doméstico.

Foram avaliadas as seguintes características de qualidade: $\mathrm{pH}$ - determinado na polpa processada e diluída na proporção de 1:1 (polpa:água destilada), utilizando-se de um potenciômetro digital, marca Micronal; a acidez titulável foi determinada pelo método volumétrico por titulação com $\mathrm{NaOH} 0,1 \mathrm{~N}$, e os valores foram expressos em \% (percentagem) de ácido cítrico (IAL, 2005); os açúcares totais foram determinados pelo método da antrona, segundo metodologia descrita por Yemn e Willis (1954), e os resultados foram expressos em percentagem de açúcares solúveis; a leitura da cor foi realizada na polpa triturada em aparelho colorímetro MiniScan EZ, e os valores foram expressos em coordenada-padrão CIE L* $a^{*} b^{*}$, medidos de acordo com diagrama de cromaticidade, em que $L^{*}$ (luminosidade) representa o brilho da superfície $\left(\mathrm{L}^{*}=0\right.$ - preto e $\mathrm{L}^{*}=100$ branco); a* variando de -60 (direção do verde) e +60 (direção do vermelho) e b* variando de - 60 (direção do azul) e +60 (direção do amarelo) (CIE, 1986); a extração dos carotenoides foi realizada em funil de separação em ambiente com redução de luminosidade, seguindo protocolo do Laboratório de Fisiologia e Tecnologia Pós-Colheita da EMBRAPA-Agroindústria Tropical, e os valores expressos em $\mathrm{mg} \cdot 100 \mathrm{~g}^{-1}$; para a obtenção dos teores de polifenóis extraíveis totais, a polpa foi liofilizada e desengordurada com hexano em refluxo, no tubo de soxlet. A extração dos polifenóis foi realizada com metanol $(50 \%)$ e acetona (70\%), sendo a quantificação feita pelo método Folin-Ciocateau. A leitura foi realizada em espectrofotômetro com leitor de microplacas a 700 $\mathrm{nm}$, e os valores, expressos em mg de ácido gálico por $100 \mathrm{~g}^{-1}$ (RUFINO et al., 2006).

Utilizou-se um delineamento inteiramente casualizado, em esquema fatorial $3 \times 6$, sendo três tipos de acondicionamento e seis períodos de armazenamento, com três repetições, totalizando 18 tratamentos. Cada amostra constou de um produto embalado contendo aproximadamente $500 \mathrm{~g}$ dos caroços e $80 \mathrm{~g}$ para polpa a vácuo.

Os resultados das avaliações de características de qualidade foram submetidos a análises de variância e regressão através de software SISVAR 3.01. Os modelos das regressões foram selecionados baseados na significância dos coeficientes de regressão, utilizando-se do teste de Tukey, ao nível de 5\% de probabilidade, e coeficiente de determinação $\left(\mathrm{R}^{2}\right)$. O procedimento de ajustamento de curvas de resposta para os tempos de armazenamento foi realizado através do software Table Curve. O teste de Tukey $(p<0,05)$ foi utilizado para comparar as médias dos tipos de acondicionamento.

\section{RESULTADOS E DISCUSSÃO}

A partir da análise de variância, foi observado que, para as características potencial hidrogeniônico $(\mathrm{pH})$, acidez titulável (AT), açúcares totais (AT) e luminosidade ( $\left.\mathrm{L}^{*}\right)$, houve interação significativa $(p<0,05)$ entre os tipos de acondicionamento e o tempo de armazenamento dos caroços e lâminas de pequi congelados. As variáveis carotenoides totais e polifenóis extraíveis totais foram influenciadas significativamente $(\mathrm{p}<0,05)$ pelos tratamentos, enquanto o parâmetro $b$ * foi influenciado somente pelo tempo.

Observou-se tendência de queda significativa $(\mathrm{p}<0,05)$ do $\mathrm{pH}$ ao longo do armazenamento, em todos os tratamentos. O decréscimo foi mais acentuado nos tratamentos caroço em bandeja com filme de PVC, com redução de 6,87 no tempo inicial, para 5,86 no final do armazenamento e caroço a vácuo, com variação de 6,68 na primeira avaliação, para 6,55 aos 300 dias de armazenamento. O tratamento da polpa em lâminas acondicionadas a vácuo apresentou menor variação de $\mathrm{pH}$, de 4,66 no início, a 4,26 ao final do armazenamento, respectivamente (Figura 1A). Provavelmente, esse comportamento deve-se ao uso do ácido cítrico (10\%), aplicado nas lâminas das polpas.

Vera et al. (2007), estudando as características físico-químicas, e Gonçalves et al. (2010), estudando os efeitos dos tipos de congelamento em Caryocar brasiliense Camb, observaram valores médios do pH de 6,58 e 6,97, respectivamente. Esses últimos autores verificaram, ainda, aumento do $\mathrm{pH}$ durante os 6 meses de armazenamento. A contradição pode ser explicada pelo estádio de amadurecimento do fruto, tendo em vista que parte dos frutos, utilizados pelos referidos autores foram colhidos na planta e outra parte foi coletada no chão e armazenados por mais três dias em condições ambientes. Em contrapartida, os frutos obtidos para este trabalho foram coletados no chão, quando se desprenderam da planta, o que sugere um estádio mais avançado de maturação.

Observou-se um incremento dos teores da acidez titulável, no acondicionamento da polpa em lâminas a vácuo até os 150 dias de armazenamento, seguido de uma queda até os 300 dias de armazenamento. Nos tratamentos caroço a vácuo e em bandeja com filme de PVC, verificou-se um aumento dos teores da acidez titulável, não ocorrendo, todavia, ajuste a nenhum modelo estatístico, por apresentarem baixos coeficientes de determinação $\left(\mathrm{R}^{2}<0,70\right)$ e falta de ajustes significativos $(p<0,05)$ (Figura 1B). Os teores mais elevados de acidez titulável encontrados no acondicionamento das lâminas a vácuo, prova- 
velmente, devem-se a resíduos do ácido cítrico, por ocasião da imersão das lâminas da polpa, numa solução contendo $10 \%$ desse ácido orgânico. Os teores de acidez verificados na presente pesquisa estão bem abaixo dos verificados por Gonçalves et al. (2010) em pequis (C. brasilense) congelados por ar forçado e por ar estático, durante 6 meses, que observaram valor inicial de $1,41 \%$ e valor final de $1,37 \%$.

Durante o armazenamento, observa-se uma variação significativa $(\mathrm{p}<0,05)$ nos teores de açúcares totais, sendo mais acentuada nos tratamentos do caroço a vácuo e do caroço em bandeja com filme de PVC. No acondicionamento do caroço a vácuo, os valores de açúcares totais reduziram-se de 3,33\% no tempo inicial para 3,01\% no final do armazenamento, com queda de $9 \%$, enquanto no acondicionamento do caroço em bandeja a redução foi de 3,76\% no início do armazenamento, para 2,71\% no final do armazenamento, sendo a redução de $28 \%$. Com relação ao acondicionamento da polpa em lâminas a vácuo, observa-se uma tendência de estabilidade, sendo o valor inicial de $1,53 \%$, e o valor aos 300 dias de armazenamento foi de 1,52\% (Figura 1D). Os menores valores de açúcares totais observados neste tratamento devem-se, provavelmente, ao corte para a obtenção das lâminas, imersão em solução de hipoclorito, lavagem e centrifugação, que contribuíram para perdas de parte do fluido celular.

Com relação aos carotenoides, observa-se que o tratamento da polpa em lâminas a vácuo diferiu dos demais com menor valor médio $\left(0,31 \mathrm{mg} \cdot 100 \mathrm{~g}^{-1}\right)$, enquanto os tratamentos do caroço a vácuo e em bandeja com filme de PVC não diferiram estatisticamente $(p<0,05)$ entre si, com valores médios, obtidos a partir da base úmida, de 0,68 e $0,73 \mathrm{mg} \cdot 100 \mathrm{~g}^{-1}$, respectivamente.

Oliveira et al. (2006) constataram que o grau de maturação de pequi $C$. brasiliense influencia no teor de carotenoides presentes na polpa. Esses autores encontraram valores de carotenoides totais de $6,78 \mathrm{mg} \cdot 100 \mathrm{~g}^{-1}$ para frutos coletados na árvore, $8,37 \mathrm{mg} \cdot 100 \mathrm{~g}^{-1}$ para frutos coletados no chão e 11,34 $\mathrm{mg} \cdot 100 \mathrm{~g}^{-1}$ para frutos coletados no chão após queda natural e três dias de armazenamento em condições ambiente. Por meio deste estudo, percebe-se a importância de haver um controle das variáveis de coleta dos frutos, que influenciam diretamente em sua composição química. Esses valores estão bem acima dos verificados neste trabalho; entretanto, a espécie C. brasiliense é conhecida pela coloração alaranjada dos pirênios, confirmando os elevados teores de carotenoides.

Gonçalves et al. (2010) verificaram decréscimo nos teores de carotenoides totais e $\beta$ - caroteno de pequi ( $C$. brasiliense) congelados e armazenados por seis meses, sendo que o congelamento por ar forçado foi melhor na preservação dos carotenoides totais (11; $\left.36 \mathrm{mg} \cdot 100 \mathrm{~g}^{-1}\right)$ e $\beta$-caroteno $\left(2,6 \mathrm{mg} \cdot 100 \mathrm{~g}^{-1}\right)$, quando comparados com os valores de congelamento por ar estático, sendo $10,81 \mathrm{mg} \cdot 100 \mathrm{~g}^{-1}$ para carotenoides totais e $1,92 \mathrm{mg} \cdot 100 \mathrm{~g}^{-1}$ para $\beta$-caroteno.

Somente o tipo de acondicionamento influenciou nos teores de polifenóis da polpa e dos frutos congelados. Os tratamentos foram significativamente $(p<0,05)$ diferentes, sendo o tratamento da polpa a vácuo com menor valor médio $\left(69,56 \mathrm{mg} \cdot 100 \mathrm{~g}^{-1}\right)$, seguido do tratamento do caroço em bandeja com filme de PVC $\left(82,48 \mathrm{mg} \cdot 100 \mathrm{~g}^{-1}\right)$ e o tratamento do caroço acondicionado a vácuo com $94,82 \mathrm{mg} \cdot 100 \mathrm{~g}^{-1}$.

Os teores de polifenóis da presente pesquisa foram próximos aos verificados por Oliveira et al. (2010) em seu estudo de caracterização do pequi $(C$. coriaceum) da Chapada do Araripe, que observaram valores médios de polifenóis extraíveis totais de $104,12 \pm 36,2112 \mathrm{mg} \cdot 100 \mathrm{~g}^{-1}$.

Durante o armazenamento, observou-se oscilação dos valores de $\mathrm{L}^{*}$ em todos os tratamentos, com tendência de redução mais acentuada no tratamento do caroço em bandeja, em que a queda foi de 64,16 no início para 50,34 no final do armazenamento, sendo o menor valor aos 240 dias $(45,46)$. O tratamento da polpa em lâminas a vácuo teve variação de 66,49 no dia da embalagem para 63,16 aos 300 dias de armazenamento, sendo o menor valor de $\mathrm{L}^{*}$ aos 120 dias $(43,11)$. O tratamento do caroço a vácuo apresentou incremento dos valores de $\mathrm{L}^{*}$, sendo a variação de 59,25 no tempo inicial para 64,57 no final do armazenamento, não ocorrendo, todavia, ajuste a nenhum modelo estatístico, por apresentarem baixos coeficientes de determinação $\left(\mathrm{R}^{2}<0,70\right)$ e falta de ajustes significativos $(\mathrm{p}<0,05)$ (Figura 1E).

Gonçalves et al. (2010) verificaram maiores valores de $\mathrm{L}^{*}$ nas amostras de pequis ( $C$. brasiliense) congelados por ar forçado $(67,32)$, enquanto no congelamento por ar estático, o valor médio foi de 65,26; além disso, verificaram redução linear dos valores de $\mathrm{L}^{*}$ durante o período de armazenamento, indicando tendência de escurecimento dos frutos, independentemente do método de congelamento. Sousa et al. (2012) observaram valores de luminosidade da polpa de pequi proveniente do município do Crato, de 69,82. Estes valores são semelhantes aos encontrados nesta pesquisa.

O parâmetro $b^{*}$ foi influenciado somente pelo tempo de armazenamento. Independentemente dos tratamentos, observaram-se oscilações significativas $(p<0,05)$ desse parâmetro com tendência de aumento durante o armazenamento. Os valores variaram entre 
11,99 aos 60 dias e 16,69 aos 300 dias de armazenamento (Figura 1F).

Sousa et al. (2012) e Oliveira et al. (2010), avaliando as características físico-químicas e químicas de pequis (C. coriaceum), oriundos da região do Cariri Cearense, verificaram valores médios do parâmetro b* de 33,49 e 27,89, respectivamente. Gonçalves et al. (2010) verificaram redução dos valores de $\mathrm{b}^{*}$ em pequis ( $C$. brasiliense) congelados e armazenados por seis meses. A variação foi de 62,07 na primeira avaliação para 33,57 aos 6 meses de armazenamento. Esses valores estão bem acima dos verificados neste trabalho.
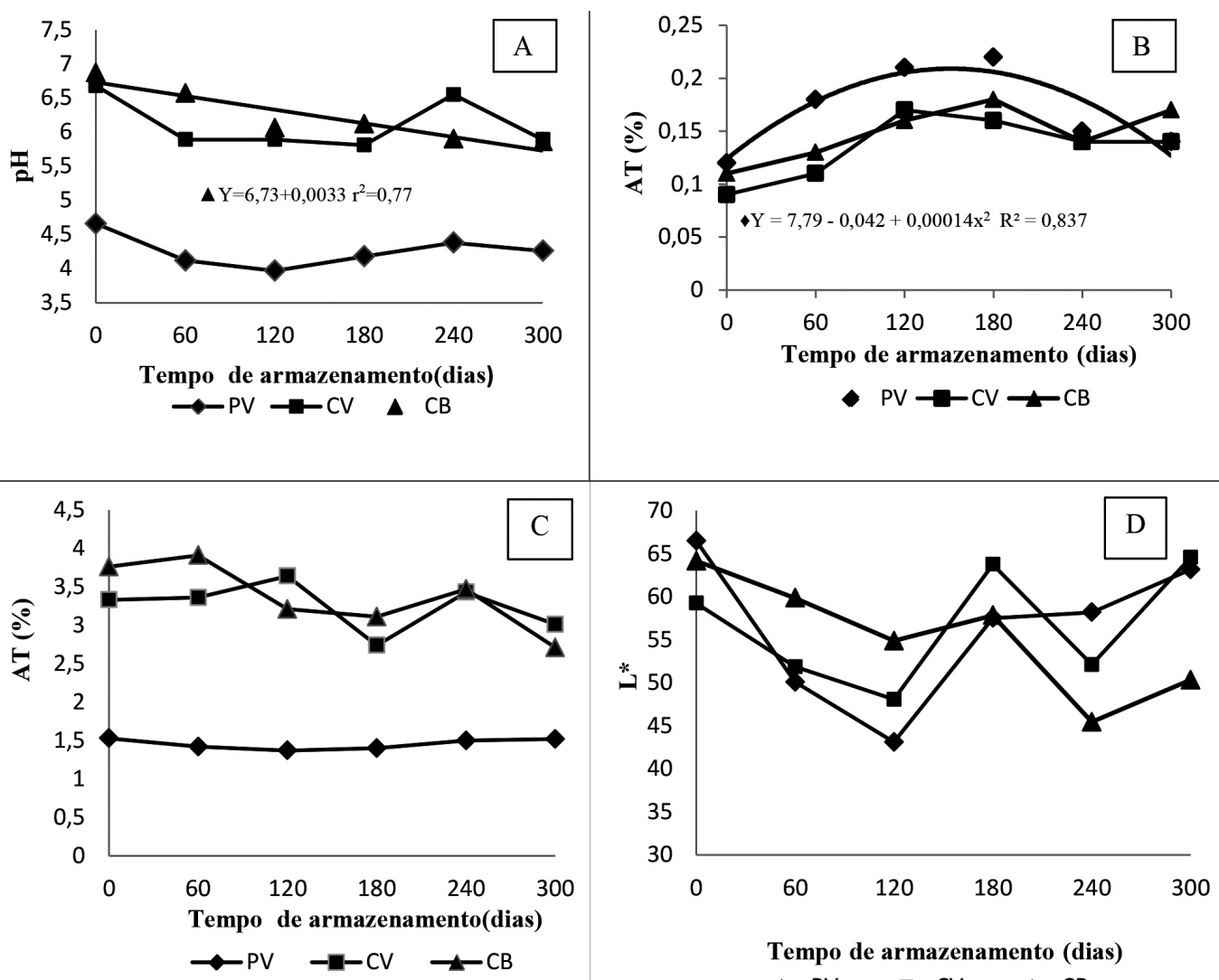

Tempo de armazenamento (dias)
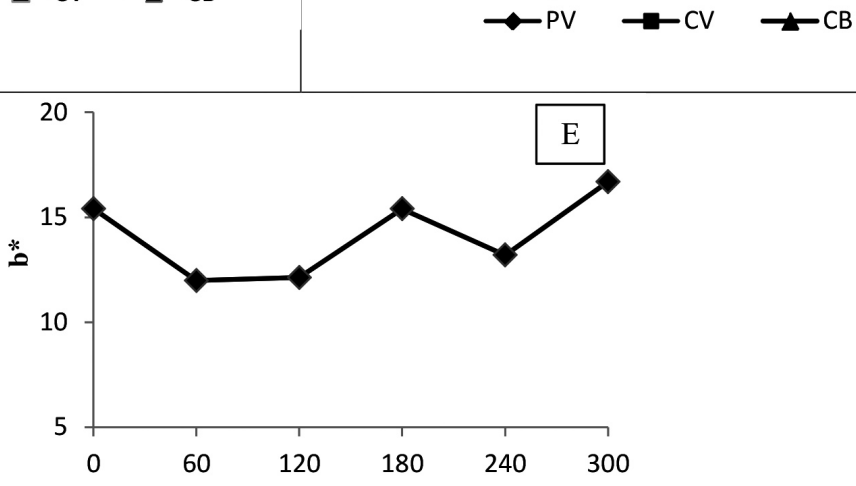

Tempo de armazenamento (dias)

FIGURA 1 - pH (A); Acidez titulável (\% de ácido cítrico) (B); Açúcares totais (\%) (C); luminosidade (L*) (D); e parâmetro b* (E); polpa em lâminas a vácuo (PV); caroço a vácuo $(\mathrm{CV})$; caroço em bandeja (CB) de frutos de pequizeiro (Caryocar coriaceum) congelados em função do tempo de armazenamento, provenientes da Chapada do Araripe, no Estado do Ceará (Fortaleza, 2010). 


\section{CONCLUSÕES}

1-O congelamento do pequi em diferentes tipos de embalagens é eficiente na preservação das características de qualidade de: $\mathrm{pH}$, acidez titulável e açúcares totais, durante 300 dias de armazenamento.

2-Os teores de carotenoides e polifenóis extraíveis totais têm redução mais acentuada no acondicionamento da polpa, em lâminas a vácuo.

3-A forma mais indicada de congelamento do pequi para a manutenção da cromaticidade é o acondicionamento do caroço a vácuo ou em bandeja com filme de PVC.

\section{REFERÊNCIAS}

CIE - Commission Internationale de I'Éclairage. Colorimetry. $2^{\text {rd }}$ ed. Vienna, 1986.78 p.

COLLA, L. M.; HERNÁNDES, C. P. Congelamento e descongelamento: sua influência sobre os alimentos. Vetor, Rio Grande, v.13, p. 53-66, 2003.

DELGADO, A. E.; SUN, P. Health and transfer models for predicting freezing process- A review. Journal of Food Engeneering, Essex, v. 47, n.1, p.157-174, 2001.

GONÇALVES, G. A. S.; VILAS BOAS, E. V. de L.; RESENDE, J. V. de; MACHADO, A. L. de L.; VILAS BOAS, B. M. Qualidade de pequi submetido ao cozimento após congelamento por diferentes métodos e tempos de armazenamento. Revista Ceres, Viçosa, MG, v. 57, p. 581-588, 2010.

IAL - Instituto Adolf Lutz. Normas analíticas, métodos químicos e físicos para análises de alimentos. 3. ed. São Paulo, 2005. 1533p.

OLIVEIRA, M. E. B. de ; GUERRA, N. B.; MAIA, A. H. N.; ALVES, R. E.; SANTOS, N. M. dos; SAMPAIO, F. G. M.; LOPES, M. M. T. Características químicas e físico-químicas de pequis da Chapada do Araripe-CE. Revista Brasileira de Fruticultura, Jaboticabal, v.32, n. 1, p.114-125, 2010.
OLIVEIRA, M. E. B. de; GUERRA, N. B.; MAIA, A. de H. N.; ALVES, R. E.; XAVIER, D. da S.; MATOS, N. M. DOS S. Características físicas de frutos de pequizeiro nativos da Chapada do Araripe-CE. Revista Brasileira de Fruticultura, Jaboticabal, v.31, n. 4, p.1196-1201, 2009.

OLIVEIRA, M. N. S. de; GUSMÃO, E.; LOPES, P. S. N.; SIMÕES, M. O. M.; RIBEIRO, L. M.; DIAS, B. A. S. Estádio de maturação dos frutos e fatores relacionados aos aspectos nutritivos e de textura da polpa de pequi (Caryocar brasiliense Camb.). Revista Brasileira de Fruticultura, Jaboticabal, v.28, n. 3, p.380-386, 2006.

RUFINO, M. S.; ALVES, R. E.; BRITO, E. S.; MANCINI FILHO, J.; MOREIRA, A. V. B. Determinação da atividade antioxidante total em frutas no sistema $\beta$-caroteno/ácido linoleico. Fortaleza: EMBRAPA Agroindústria Tropical, 2006. (Comunicado Técnico, 126).

SOUSA, F. C. de; SILVA, L. M. de; SOUSA, E. P. de; LIMA, A. N. V. de O.; FIGUEREDO, R. M. F. de; Parâmetros físicos e físico-químicos de polpa de pequi. Revista Verde, Mossoró, v. 6, n. 1, p.12-15, 2012.

VERA, V.; SOUZA, E. R. B. de; FERNANDES; E. P.; NAVES, R. V.; SOARES JÚNIOR, M. S.; CALIARI, M.; XIMENES, P. A. Caracterização física e química de frutos de pequizeiro (Caryocar brasiliense Camb) oriundos de duas regiões no Estado de Goiás, Brasil. Pesquisa Agropecuária Tropical, Goiânia, v. 37, n.2, p. 93-99, 2007.

SILVA, M. A. P. da; MEDEIROS FILHO, M. S. Morfologia do fruto, semente e plântula de pequi (Caryocar brasiliense, Wittm). Revista Ciência Agronômica, Fortaleza, v. 37, n. 3, p. 320-325, 2006.

YAMASHITA, F. et al. Produtos de acerola: estudo da estabilidade da vitamina C. Ciência e Tecnologia de Alimentos, Campinas, v.23. n.1, p.92-94, 2003.

YEMN, E.W.; WILLIS, A.J. The estimation of carbohydrate in plant extracts by anthrone. The Biochemical Journal, London, v.57, p. 508-514, 1954. 